\title{
Study of ventilation reversion of airflow in mining roadways and tunnels by CFD and experimental methods
}

\author{
S. Torno, J. Toraño \& J. Velasco \\ School of Mines, University of Oviedo, Spain
}

\begin{abstract}
When a mining roadway and tunnel is being advanced or has already been carried out, the air circulation direction can be inverted for different reasons, the most frequent being, the outburst of pollutant gases and the effect of a fire.

This reversion effect can become serious for the workers. The behaviour analysis of this ventilation by conventional methods presents deficiencies which can be improved by CFD (Computational Fluid Dynamics) by using Ansys CFX 10.0 software with the establishment of prediction models.

The CFD modelling were validated by mining roadway measurements using anemometers, methanometers and oxymeters.

It has been proved that the mining roadway or tunnel longitude reached by the reversion of airflow is reduced by installing an auxiliary forcing ventilation overlapped with the main ventilation. Additionally, it has been determined that the longitude is not reduced by increasing the main ventilation velocity.

Likewise, different tests to check the effect of different types of auxiliary ventilation system over the roadway longitude reduction, have been carried out.
\end{abstract}

Keywords: underground ventilation, reversion of airflow, CFD3D (Computational Fluid Dynamics), mining roadway.

\section{Introduction}

In the driving tunnel with a longitudinal type of ventilation, the air flows along intake airway (tunnel or roadway 1) to the working area and the contaminated air passes back along return airways (parallel tunnel or mining roadway 2 ). The roadway (3) joins (1) and (2), it can be seen in figure 1. In this working area, a significant pollutant gas (methane) emission has been produced $[1,2]$ which has 


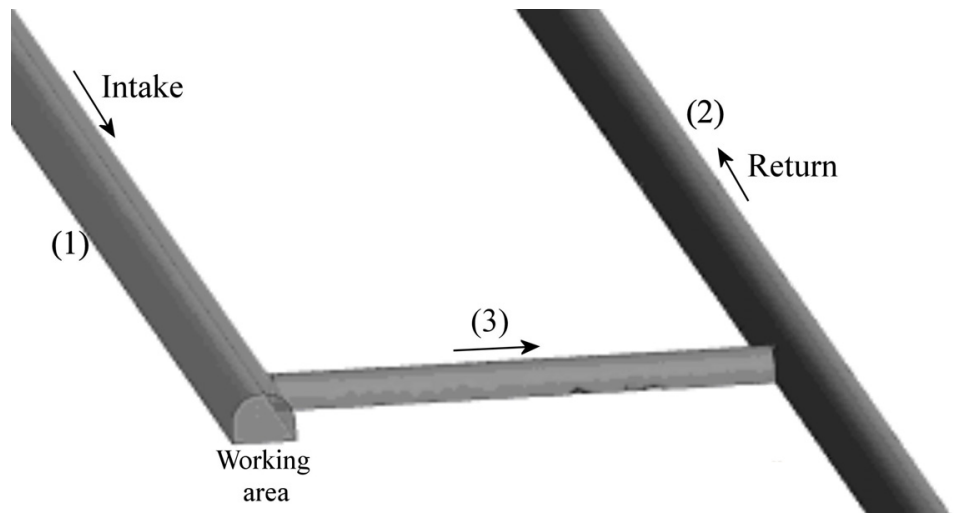

Figure 1: Geometry and model description.

caused the circulation flow direction of intake in the roadway or tunnel (1) to become inverted instead of flowing out through the roadway or tunnel (2), causing a great danger to the workers [3-5].

The study and analysis of the latter and the possible solutions by mean of conventional methods present clear deficiencies which should be improved through computational numerical methods, Computational Fluid Dynamics (CFD).

The flow behaviour is modelized by software Ansys CFX-10.0 utilizing the K-epsilon turbulence model, as has already been carried out by other [6-9].

In this paper, the effect of the reversion on the workers working at the end tram of the roadway is analysed. In addition, as the roadway or tunnel longitude of reversion (1) varies when safety measures such us ventilation duct outlet airflow modification are introduced, since in this case the use of methane drainage installing systems are not possible.

The study and analysis of the latter and the possible solutions by mean of conventional methods present clear deficiencies which should be improved through computational numerical methods, CFD.

The flow behaviour is model zed by software Ansys CFX-10.0 utilizing the K-epsilon turbulence model, as has already been carried out by other [6-9].

In this paper, the effect of the reversion on the workers working at the end tram of the roadway is analysed. In addition, as the roadway or tunnel longitude of reversion (1) varies when safety measures such us ventilation duct outlet airflow modification are introduced, since in this case the use of methane drainage installing systems are not possible.

\section{CFD Modelling and underground field measurement}

The CFD based on the resolution of set of equations which describe the processes of momentum, heat and mass transfer in a moving fluid are known as the Navier-Stokes equations, [12] eqn (1), Continuity, eqn (2) and Energy eqn (3). 


$$
\begin{gathered}
\rho \frac{\mathrm{D} \overline{\mathrm{V}}}{\mathrm{Dt}}=-\bar{\nabla} \mathrm{p}+\rho \overline{\mathrm{g}}+\mu \nabla^{2} \overline{\mathrm{V}} \\
\frac{\mathrm{D} \rho}{\mathrm{Dt}}+\rho \bar{\nabla} \cdot \overline{\mathrm{V}}=0 \\
\rho \frac{\mathrm{D} \widetilde{\mathrm{u}}}{\mathrm{Dt}}=\mathrm{K} \nabla^{2} \mathrm{~T}-\mathrm{p} \bar{\nabla} \cdot \overline{\mathrm{V}}
\end{gathered}
$$

where $\rho$ is the density, $\nabla \cdot$ is the operator divergence, $\nabla$ is the gradient, $\mu$ is the viscosity, $T$ is the temperature, $t$ is the time, $V$ is the velocity, $\tilde{u}$ is the specific heat and $K$ is the conductivity.

These partial differential equations have no known general analytical solution but can be discretized and solved numerically.

These expressions form a partial differential equation system, which is coupled for linear form, and therefore CFD is used for the solutions.

This is a multiphase problem, where a two phase flow, air and pollutant (methane) is modelled. The software Ansys CFX-10.0 has two multiphase flow models available, the Eulerian-Eulerian multiphase model and the Lagrangian Particle Tracking multiphase model. In other researches carried out where one of the phases is dust particle, the Lagrangian Tracking multiphase model has been used, whereas in this paper, Eulerian-Eulerian multiphase model is used.

Within this model, certain interphase transfer terms used in interphase transfer models, are modelled using the Mixture Model, which symmetrically deals with the phases, but merely for continuous phases.

The CFD Modelling commence with a geometry carried out by SolidWorks, which is posteriorly meshed by ICEMCFD-10.0 with approximately 500000 elements and a finer meshing for the auxiliary ventilation duct area.

The resulting model is characterised in software Ansy CFX-10.0, by 3 different boundary conditions, Inlet, Opening and Wall. In this model, there are 3 Inlets, one fresh air inlet and two pollutant inlets. The Opening corresponds to the model flow outlet and the remaining surfaces are Wall.

In figure 2 the coloured streamlines in velocity function according to longitudinal direction of the roadway are shown. Furthermore, the reversion areas can be seen as streamline interaction, represented by two arrows.

Having carried out the modelling, the results are compared to real data, which have been collected in the mining roadway by means of various instruments Miniar Junior Macro-MIE handheld anemometers, Trolex 6383.01 methane detectors and Trolex 6531 oxygen detectors.

The comparison between CFD values and (EXP) Experimental values, giving us a correlation $\mathrm{R}^{2}=0.9833$, which is adjusted to the following equation, Eqn (4), have been developed:

$$
\mathrm{CFD}=0.7168 \cdot \mathrm{EXP}+12.681
$$




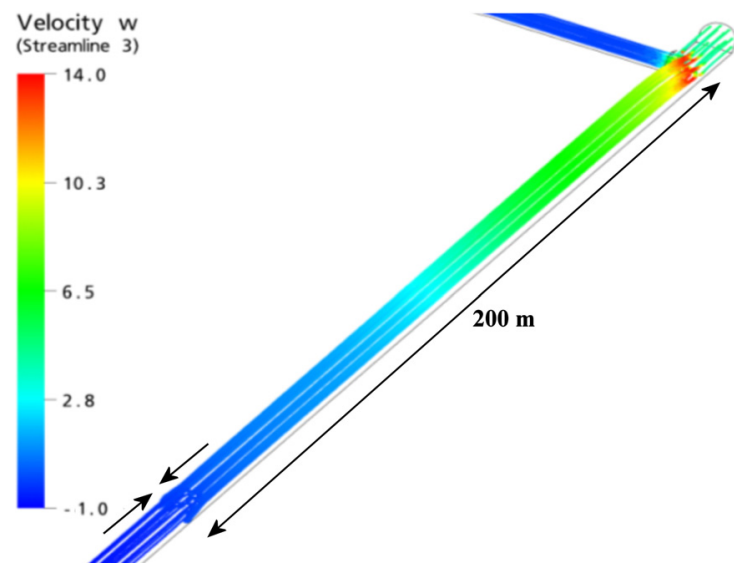

Figure 2: $\quad$ Longitude of reversion.

\section{Effect of roadway (3) for ventilation reversion}

The effect of the reversion of airflow for the final roadway tram has been studied for its repercussion for the security of workers and it is also a significant reason for the use of CFD model adjusted by experimental tests.

The importance of this study being carried out away from the pollutant emission source is due to the fact that two workers were working in the roadway at the time of the incident.

However, these workers were not affected by the oxygen reduction produced during the reversion. Additionally, data collected by a methanometer (at that time) have been used to validate modelization for this roadway tram.

In figure 3 , the obtained results by CFD modelling for the final roadway tram where the reversion of airflow was produced is shown. A papallel plane to floor at $1 \mathrm{~m}$ high can be seen where the velocity distribution for both the roadway longitudinal direction and the streamlines, are shown. In tram (I), the velocity

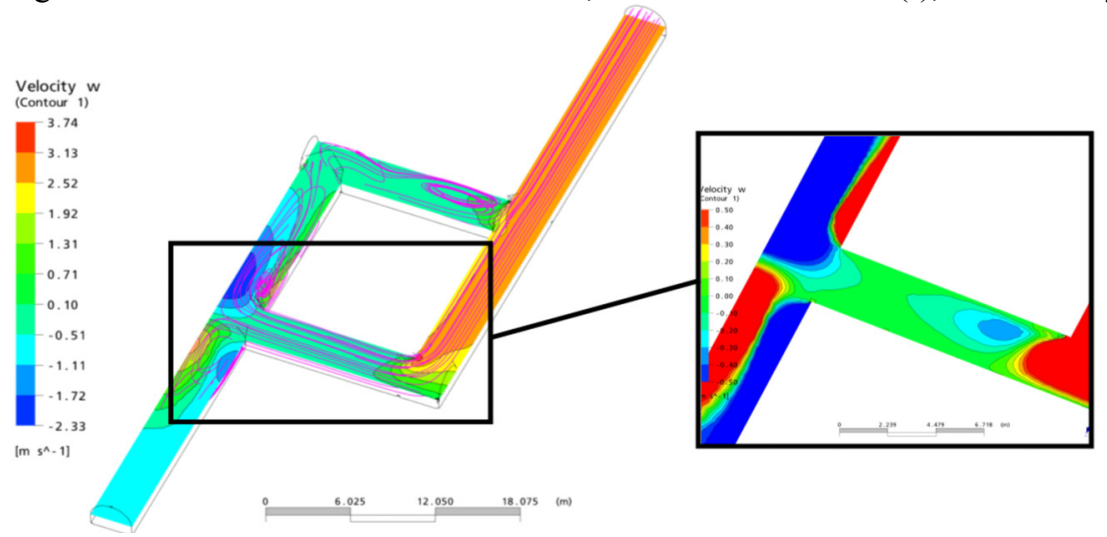

Figure 3: Modelization of roadway final tram. 
flow $(3.74 \mathrm{~m} / \mathrm{s})$, which diminishes when the flow is divided by the two roadways, even causing a change of direction resulting in negative values.

If cross-sections are analyzed in figure 3, the flow distribution for tram (I) can be studied.

The study cross-sections are S1, S2, S3, S4.1, S4.2, S5, S6 and S7, are shown in figure 4 . In this figure, cross-section of the roadway longitudinal direction velocity is shown.
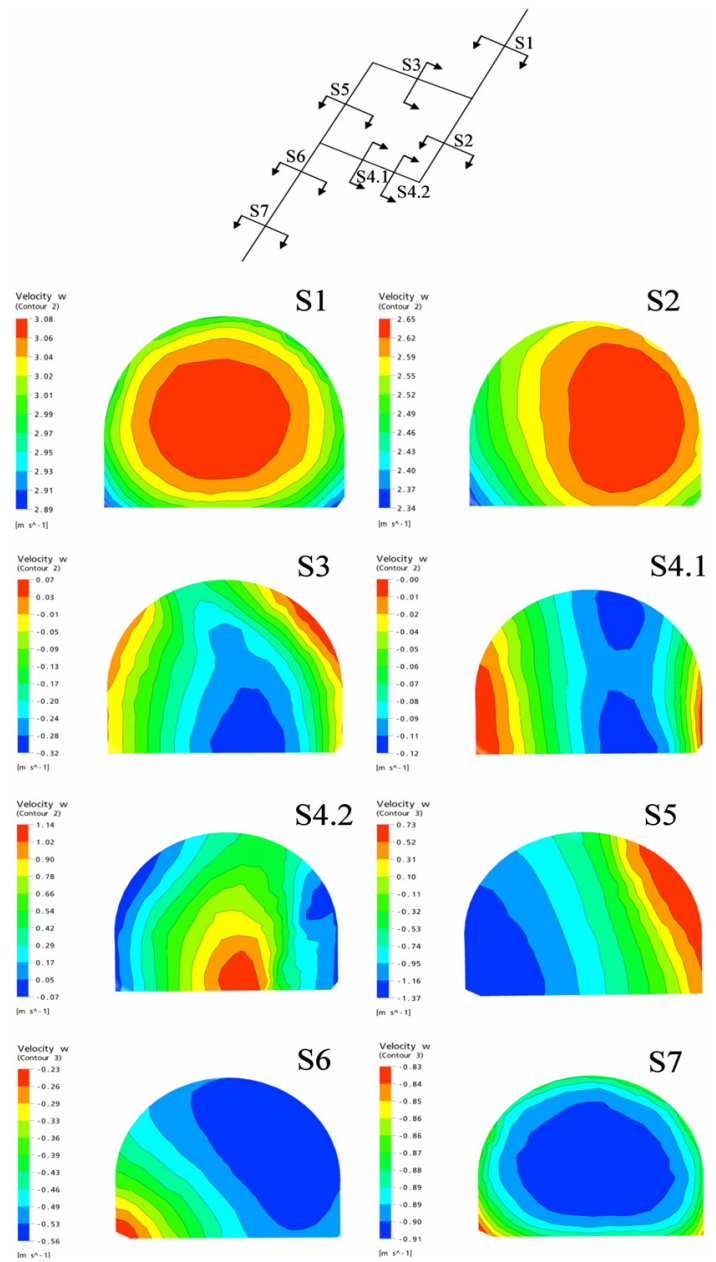

Figure 4: Velocity cross-section for the roadway final tram.

For cross-sections S1 and S2, the high velocity is found in the central area of the roadway, where the greater amount of pollutant is concentrated. When the flow is divided by cross-section S3 and S4 its distribution changes, lower and even negative velocities are present in the central roadway areas. It is considered to be of great significance for cross-section S4 (S4.1 and S4.2), since the latter workers were working in this area at the time of the incident. 
In cross-section, S5, S6 and S7, the amount of fresh air increases, reaching a total flow recovery for cross-section.

As it can be proved, the obtained and adjusted model coincides with the facts, observed in the mine where a greater ventilation reversion is produced. Therefore, the methane influence is found in the central zone of the roadway. In this way, it has been indicated that the workers were not affected by the methane emerging from the reversion of airflow.

\section{Effect of an auxiliary forcing ventilation system over the reversion of airflow}

An auxiliary forcing ventilation system overlapped with the main ventilation in roadway (1) has been incorporated in order to diminish the roadway longitude where the reversion of airflow is produced. This auxiliary ventilation consists of a $400 \mathrm{~mm}$ diameter and $60 \mathrm{~m}$ long duct.

Two different modellings with 12 and $20 \mathrm{~m} / \mathrm{s}$ velocity at the auxiliary duct outlet have been carried out.

The results have shown a $74 \mathrm{~m}$ reversion reduction for $12 \mathrm{~m} / \mathrm{s}$ velocity, whereas for $20 \mathrm{~m} / \mathrm{s}$ velocity a $78 \mathrm{~m}$ reduction was shown, (the reversion being $120 \mathrm{~m}$ from the roadway 3 ). The $20 \mathrm{~m} / \mathrm{s}$ velocity has been chosen to be installed in the underground coal mine.

In figure 5, the streamline flow distribution for the $20 \mathrm{~m} / \mathrm{s}$ velocity is shown, where the streamline of auxiliary forcing ventilation reduce the velocity of the pollutant streamline (dark colour), allowing the main ventilation streamline (clear colour) to reach a greater longitude $(158 \mathrm{~m})$.

In order to validate the results of this $20 \mathrm{~m} / \mathrm{s}$ auxiliary forcing ventilation modelling, they have been compared to real data according to Eqn (5) with a $\mathrm{R}^{2}=0.90$ value.

$$
\mathrm{CFD}=1.4247 \cdot \mathrm{EXP}-0.124
$$

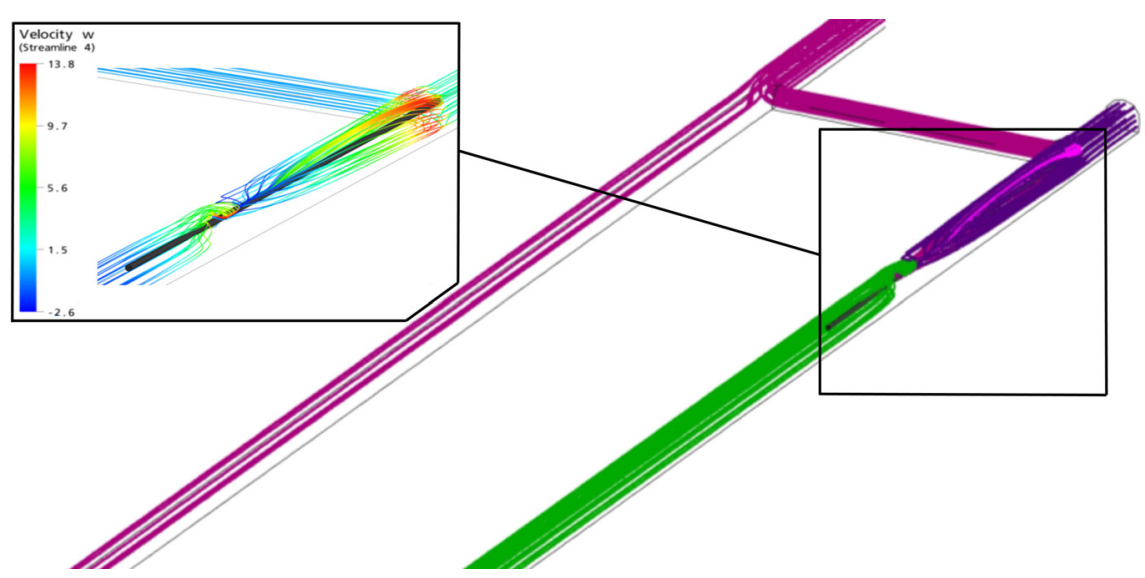

Figure 5: Streamline flow for the $12 \mathrm{~m} / \mathrm{s}$ auxiliary forcing ventilation output. 
This reduction in the roadway longitude, where the reversion is produced, can be achieved by using the $20 \mathrm{~m} / \mathrm{s}$ auxiliary forcing ventilation with favourable results. On the other hand, if the main ventilation velocity increases a good reversion reduction is not achieved.

In Table 1, a $200 \mathrm{~m}$ reversion reduction from the roadway (3) for main ventilation of 2, 3, 5 and $8 \mathrm{~m} / \mathrm{s}$ is shown. The Spanish Regulation establishes a tunnel or roadway velocity between $(0,2-8 \mathrm{~m} / \mathrm{s})$.

The 5 and $8 \mathrm{~m} / \mathrm{s}$ velocity, which most reduces the reversion longitude, is scarcely used, as they are unfavourable for the workers. Even with these high values, the reversion is not reduced as much as by introducing a $20 \mathrm{~m} / \mathrm{s}$ auxiliary ventilation over the main ventilation.

Table 1: Reversion longitude for several main velocities.

\begin{tabular}{|c|c|}
\hline Main ventilation $(\mathrm{m} / \mathrm{s})$ & Reversion longitude $(\mathrm{m})$ \\
\hline 1 & 200 \\
\hline 2 & 140 \\
\hline 3 & 118 \\
\hline 5 & 92 \\
\hline 8 & 82 \\
\hline
\end{tabular}

\section{Conclusions}

In this paper, the use of Computational Fluid Dynamics for the underground mining ventilation study, is widely proved. Additionally, a widespread study of safety measures can be carried out when a significant methane outburst occurs in tunnel or mining roadway construction.

In order to avoid ventilation reversion during the significant methane outburst, different CFD options, such as an increase in the main ventilation velocity and the incorporation of an auxiliary forcing ventilation, have been studied.

In the first case, $2,3,5$ and $8 \mathrm{~m} / \mathrm{s}$ velocities were used with no sufficiently effective velocity findings, which are a danger to the workers.

In the second case, two 12 and $20 \mathrm{~m} / \mathrm{s}$ auxiliary fans were used, achieving more favourable results for the $20 \mathrm{~m} / \mathrm{s}$.

The chosen safety measures is the $20 \mathrm{~m} / \mathrm{s}$ auxiliary forcing ventilation overlapped with the main ventilation, reducing the reversion longitude to $150 \mathrm{~m}$. This safety measure has been placed in the real tunnel achieving the expected results.

\section{References}

[1] Vandeloise, R., Compte rendu du Colloque International sur les Dégagements Instantanés. Harkany (Hungrie), Annales des Mines de Belgique. No 2 Février, 1969. 
[2] Belin, J. \& Vandeloise, R, Résultats des recherches efectúes en Belgique et en France sur les dégagements instantanés Dans les mines de charbon. Annales des Mines de Belgique. No 2 Février, 1969.

[3] Kissell, F. N., Handbook for Methane Control in Mining. U.S. Department of Health and Human Services. Public Health Service. Centers for Disease Control and Prevention. National Institute for Occupational Safety and Health. Pittsburgh Research Laboratory, 2003.

[4] Wasilewski, S., Methods and means of monitoring of gas hazards in polish underground hard coal mines. Mine Hazards Prevention and Control Technology, 17, pp. 650-654, 2007.

[5] McPherson, M.J., Subsurface Ventilation Engineering. Chapter 12 Methane, Mine Ventilation Services, Inc., 2009.

[6] Norton, T., Sun, D.W., Grant, J., Fallon, R. \& Dodd, V., Applications of computational fluid dynamics (CFD) in the modelling and design of ventilation systems in the agricultural industry. Bioresource Technology, 98, pp. 2386-2414, 2007.

[7] Moloney, K.W., Lowndes, I.S. \& Hargrave, Analysis of flow patterns in drivages with auxiliary ventilation. Transaction of the Institution of Mining and Metallurgy (Section A: Mining Industry), 108, pp. 105-114, 1999.

[8] Moloney, K.W. \& Lowndes, I.S., Comparison of measured underground air velocities and air flows simulated by computational fluid dynamics. Transaction of the Institution of Mining and Metallurgy (Section A: Mining Industry), 108, pp. 105-114, 1999.

[9] Toraño, J., Rodríguez, R. \& Diego, I., Computational Fluid Dynamics (CFD) used in the simulation of the death end ventilation in tunnel and galleries. Transaction: Engineering Sciences, 52, pp. 2006.

[10] Brunner, D.J., Schwoebel, J.J. \& Brinton, J.S., Modern CMMM strategies. $11^{\text {th }}$ North American Mine Ventilation Symposium., Eds Mutmansky and Ramani, Penn State University, 2006.

[11] Karacan, C.O., Diamond, W.D. \& Schatzel, S.J., Numerical analysis of the influence of in-seam horizontal methane drainage boreholes on longwall face emission rates. International Journal of Coal Geology, 72, pp. 15-32, 2007.

[12] Ansys CFX ANSYS CFX- Solver. Release 10.0 ANSYS CFX-Solver, Release 10.0: Modelling pp 327. 